\title{
Mineração
}

\section{Efeito da adsorção de amina no potencial zeta da hematita e do quartzo}

\author{
Rosa Malena Fernandes Lima \\ Professora do DEMIN/EM/UFOP. \\ E-mail:rosa@demin.ufop.br
}

Lucinei Quirino

Mestrando do PPGEM

\section{Resumo}

Esse trabalho teve por objetivo estudar o efeito de uma eteramina sobre o potencial zeta dos minerais hematita e quartzo. As amostras utilizadas possuíam alto grau de pureza, com granulometria na faixa de 53 a $44 \mu \mathrm{m}$. O reagente utilizado foi um acetato de eteramina a $50 \%$ de grau de neutralização. Foi utilizada a célula eletroforética, Zeta potencial - Model 1202, fabricada pela Micromeritcs. Em uma primeira fase, determinou-se a curva de potencial zeta da hematita e do quartzo, condicionados somente com água destilada. O IEP da hematita ocorreu em valores de $\mathrm{pH}$ entre 6 e 8 . Os valores de potencial zeta do quartzo foram negativos para todos os valores de $\mathrm{pH}(6 \mathrm{a}$ 12). Nos ensaios utilizando soluções de amina, observou-se que o potencial zeta dos dois minerais tornou-se menos negativo em relação aos ensaios na ausência desse reagente e que essa diminuição, no caso do quartzo, foi bem mais acentuada que a da hematita. Observou-se a mudança de sinal de negativo para positivo do potencial zeta do quartzo entre o $\mathrm{pH} 9$ e 10 para a dosagem de amina a $3,54 \times 10^{-4} \mathrm{M}$.

Palavras-chave: potencial zeta, hematita, quartzo, amina.

\begin{abstract}
The objective of this paper was to study the influence of eteramine on the zeta potential of hematite and quartz. Minerals with high purity degree, between 53 and $44 \mathrm{~mm}$ size distribution, and a 50\% neutralization degree eteramine acetate were used. The tests were carried out on an eletroforetic cell, Zeta potential-model 1202 of Micromeritics. The pulp used had $12 \% \mathrm{w} / \mathrm{w}$ solid. Initially, the zeta potential of both minerals were determined in distilled water ( $\mathrm{pH}$ from 6 to 12). The hematite IEP occurred at $\mathrm{pH}$ values between 6 and 8 and the zp of quartz was negative for all $p H$ studied. It was observed that the zeta potential of quartz became less negative in the presence of amine. At $3,54 \times 10^{-4} \mathrm{M}$ eteramine concentration, it was observed that the zeta potential of quartz changes from a negative to a positive value at $p H$ values between 9 and 10 .
\end{abstract}

Keywords: zeta potential, hematite, quartz, amine. 


\section{Introdução}

A concentração de minérios de ferro de baixo teor (itabiritos) iniciou-se nos anos 50 com a flotação direta dos minerais de ferro, usando sulfonato de petróleo em conjunto com óleo combustível, ácidos graxos e hidroxamatos como coletores. A flotação inversa de minério de ferro, que vem sendo largamente empregada pelas empresas, usando amina como coletor da sílica, começou a ser utilizada nos anos 60 (Huout, 1983).

Araújo (1982), em estudos de microflotação com os minerais quartzo e hematita, usando uma amina graxa primária com cadeia de 10 a 12 átomos de carbono, observou que a região de máxima flotabilidade para ambos minerais estava compreendida entre os valores de $\mathrm{pH}$ de 9 a 10,5. O aumento da concentração de amina levou a ampliação do intervalo de $\mathrm{pH}$ de máxima flotabilidade para o quartzo. A queda brusca de flotabilidade em valores de $\mathrm{pH}$ acima de 10,5 foi atribuída pelo autor à diminuição acentuada da concentração de espécies iônicas do coletor, conforme diagrama de $\%$ de dissociação de amina alifática em função de pH (Leja, 1983). Segundo Laskowski e colaboradores (1988), o cloreto de dodecilamina forma um precipitado coloidal para concentrações maiores que $2 \times 10^{-5} \mathrm{M}$ (limite de solubilidade), cujo ponto isoelétrico (PIE) ocorre no $\mathrm{pH} 11$, o que pode explicar a total ausência de flotabilidade da ghoetita em pH 12 observada por Iwasaki e colaboradores (1960).

Segundo Iwasaki (1960), a adsorção de amina sobre a superfície da ghoetita é de caráter eletrostático, pois a mesma se adsorve sobre a superfície do mineral em $\mathrm{pH}$ acima do PIE (6,7). Lima (1997), através de espectroscopia infravermelha a transformada de Fourier, concluiu que a adsorção do acetato de eteramina sobre as superfícies da hematita e do quartzo pode ocorrer por atração eletrostática entre os íons eteramônio e a superfície dos minerais carregada negativamente e por ligações de van der Walls entre os carbonos do cátion etermônio e da amina molecular, presentes no sistema. Quast (2000), que fez um trabalho de revisão de flotação de hemati- tas, usando diversos coletores com 12 átomos de carbono na cadeia (ácido láurico, hidroxamato, sulfato, sulfonato dodecil benzeno de sódio e um acetato de dodecilamina), disse que a precipitação de amina sobre a hematita tem um papel importante na flotação desse mineral.

Nas Figuras 1, 2 e 3, estão apresentados estudos de flotabilidade do quartzo e hematita, realizados por Lima (1997), usando um acetato de eteramina com 10 a 12 átomos de carbono na cadeia e grau de neutralização igual a 50\% (50\% da amina utilizada encontrava-se na forma de sal - acetato de eteramina - e $50 \%$ na forma molecular), fabricado pela Clariant (Flotigan EDA-B).
Observa-se que a flotabilidade da hematita atingiu cerca de $100 \%$ para valores de $\mathrm{pH}$ mais baixos (6 a 9) na dosagem de $50 \mathrm{mg} / \mathrm{l}$. Para todas as dosagens houve queda de flotabilidade para $\mathrm{pH} 11$ e 12.

Para o quartzo, observou-se queda de flotabilidade em torno de $\mathrm{pH}$ 10,5 para dosagens maiores que $5 \mathrm{mg} / \mathrm{l}$ (veja Figura 3). Rossi e colaboradores (1991) observaram que ao plotar os resultados como logarítmo da concentração de coletor (amina)em função do $\mathrm{pH}$ na flotação dos minerais scheelita, calcita, feldspato e quartzo, usando amina, são definidas áreas de flotação total, parcial ou de nenhuma flotação, que são dife-

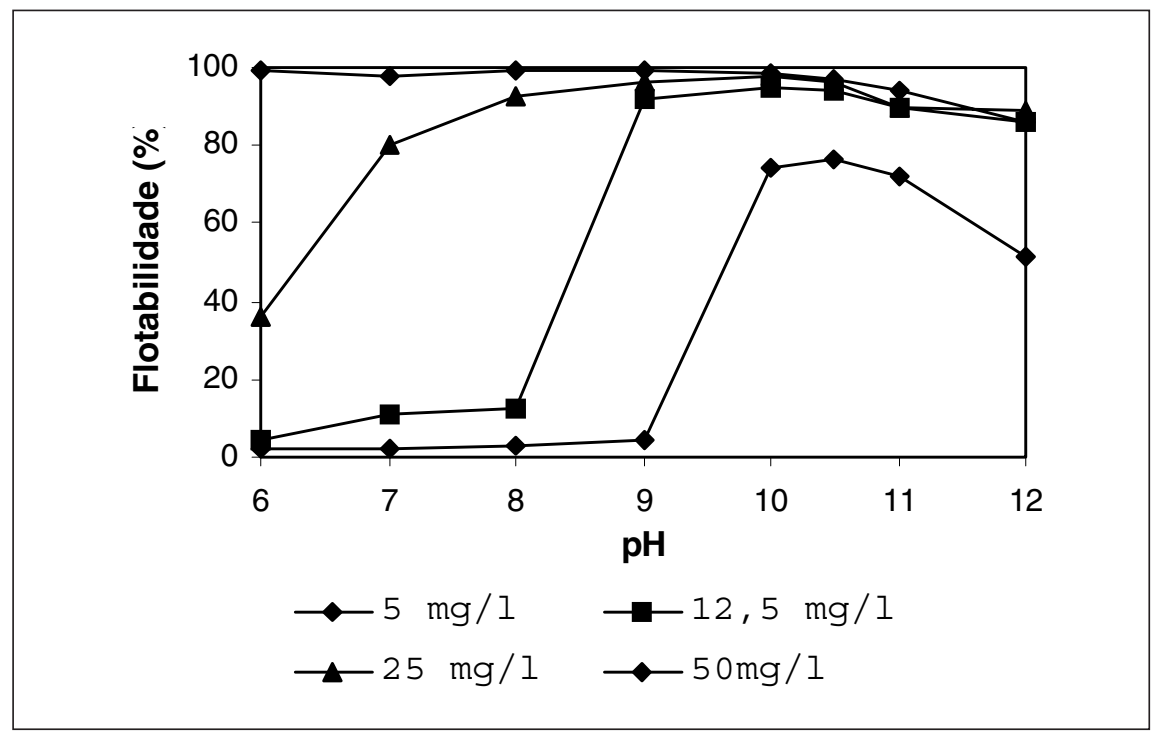

Figura 1 - Flotabilidade da hematita em função do pH e da concentração de acetato de eteramina (Lima, 1997; Lima e Brandão, 1999).

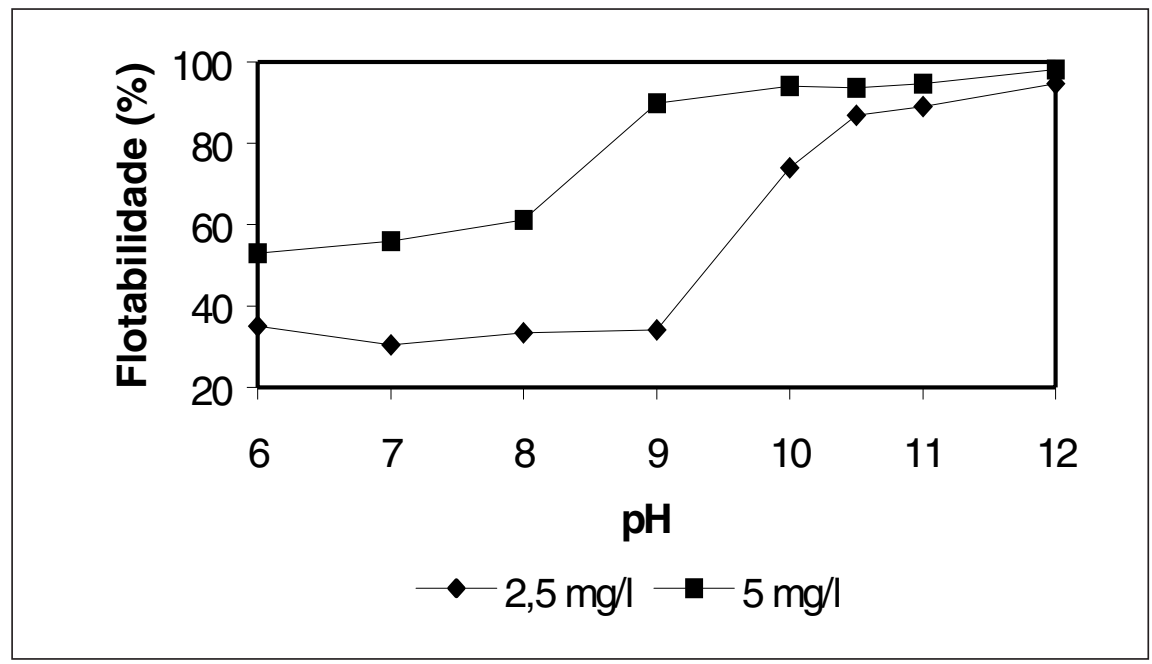

Figura 2 - Flotabilidade do quartzo em função do pH e da concentração de acetato de eteramina, Lima (1997), Lima e Brandão (1999). 
rentes para cada mineral analisado, sugerindo que uma segunda camada de coletor reduz a flotação em algumas áreas do gráfico, que são chamadas áreas de depressão. Logo, a queda de flotabilidade observada para as dosagens de 10 , 12,5 e $25 \mathrm{mg} / \mathrm{l}$ de acetato de eteramina poderia estar relacionada com a alta concentração de íons eteramônios em solução, que, após saturada a primeira camada, levaria à formação de uma segunda camada destes íons adsorvidos na superfície do mineral, tornando-a menos hidrofóbica e causando dessa forma a diminuição da flotabilidade.

Nesse trabalho estão apresentados os resultados dos estudos eletroforéticos com amostras de hematita e de quartzo condicionados com acetato de eteramina nas mesmas concentrações empregadas nos ensaios de microflotação descritos anteriormente.

\section{Materiais e metodologia}

Para os ensaios de eletroforese, foram utilizadas amostras minerais de hematita e quartzo na faixa granulométrica compreendida entre 53 e $44 \mathrm{~mm}$, mesma granulometria dos ensaios de microflotação. A amostra de hematita possuía teores de ferro total igual a $68,97 \%$, P.P.C. de $0,68 \%, \mathrm{FeO} 1,18 \%, \mathrm{SiO}_{2}$ de $0,23 \%$, $\mathrm{Al}_{2} \mathrm{O}_{3} 0,29 \%$, $\mathrm{P}$ de $0,036 \%$ e $\mathrm{Mn}_{2} \mathrm{O}_{3}$ de $0,05 \%$. Através de cálculos estequiométricos determinaram-se as proporções de hematita $(87,4 \%)$, goethita $(6,73 \%$ e magnetita $(3,80 \%)$, que são óxidos e hidróxidos de ferro, cujas propriedades superficiais são similares. A amostra de quartzo possuía teor de $98,24 \%$ de $\mathrm{SiO}_{2}, 1,37 \%$ de $\mathrm{Fe}_{2} \mathrm{O}_{3}$ e $0,182 \%$ de $\mathrm{Al}_{2} \mathrm{O}_{3}$.

Para a determinação de potencial zeta das amostras minerais em questão, na ausência e na presença de amina (acetato de eteramina comercial a 50\% de grau de neutralização, fabricado pela Clariant), utilizou-se o analisador de potencial zeta, modelo 1202 da Micromeritics. Esse equipamento é constituído por uma câmara cilíndrica de $150 \mathrm{~cm}^{3}$, denominada de câmara de transporte de massa. Em uma das extremidades dessa câmara é colocado um eletrodo redondo de zinco e na outra extremidade uma célula contendo o outro eletrodo.

O potencial zeta é calculado pela seguinte fórmula:

$\zeta=\left[\left(36 \times 10^{4}\right) \times\left(\mathrm{V}_{\varepsilon} \times \eta\right)\right] / \mathrm{D}$

Onde:

$\zeta$ - potencial zeta

$\mathrm{V}_{\varepsilon}$ - mobilidade eletroforética em $\mathrm{cm} / \mathrm{seg} / \mathrm{volt} / \mathrm{cm}$;

$\eta$ - viscosidade da suspensão em poise;

D - constante dielétrica da célula.

Como pode ser observado pela fórmula anteriormente apresentada, para a determinação do potencial zeta, faz-se necessário determinar a mobilidade eletroforética, e a viscosidade da suspensão, além da constante dielétrica da célula.

A determinação da mobilidade eletroforética $\left(\mathrm{V}_{\varepsilon}\right)$ é feita pela variação da massa da suspensão dentro da célula antes e após a aplicação de corrente elétrica. Adotase o seguinte procedimento: em uma primeira fase, preenche-se a célula com a suspensão nos valores de \% de sólidos e pH determinados, que são os mesmos valores do restante da suspensão, que será colocada dentro da câmara de transporte de massa. Tampa-se a mesma com uma pequena haste para pesagem em balança analítica. Após a pesagem da célula, a mesma é introduzida na extremidade da câmara de transporte de massa, retira-se a haste, gira-se o anteparo, existente dentro da câmara para tampar o orifício da célula, e se termina de preencher a câmara até que a suspensão cubra os eletrodos. Então, gira-se o anteparo, aplica-se a corrente pelo período de tempo preestabelecido, fecha-se de novo a câmara com o anteparo, remove-a, introduz novamente a haste e pesa-se a mesma como foi feito no início do ensaio. Depois calcula-se $\mathrm{V}_{\varepsilon}$ pela fórmula dada a seguir.

$\mathrm{V}_{\varepsilon}=\left[\left(\Delta \mathrm{w}\right.\right.$. D) / [(Resistância da suspensão . t . I . v . (1- v). $\left.\left(\rho_{\mathrm{p}}-\rho_{1}\right)\right]$

Onde:

$\Delta \mathrm{w}$ - variação de massa da célula $(\mathrm{g})$;

$\mathrm{t}$ - duração do ensaio em segundos;

I - corrente em ampers;

V - fração volumétrica de sólido;

$\rho_{\mathrm{p}}$ - densidade da polpa ou suspensão em $\mathrm{g} / \mathrm{cm}^{3}$;

$\rho_{1}$ - densidade do líquido em $\mathrm{g} / \mathrm{cm}^{3}$.

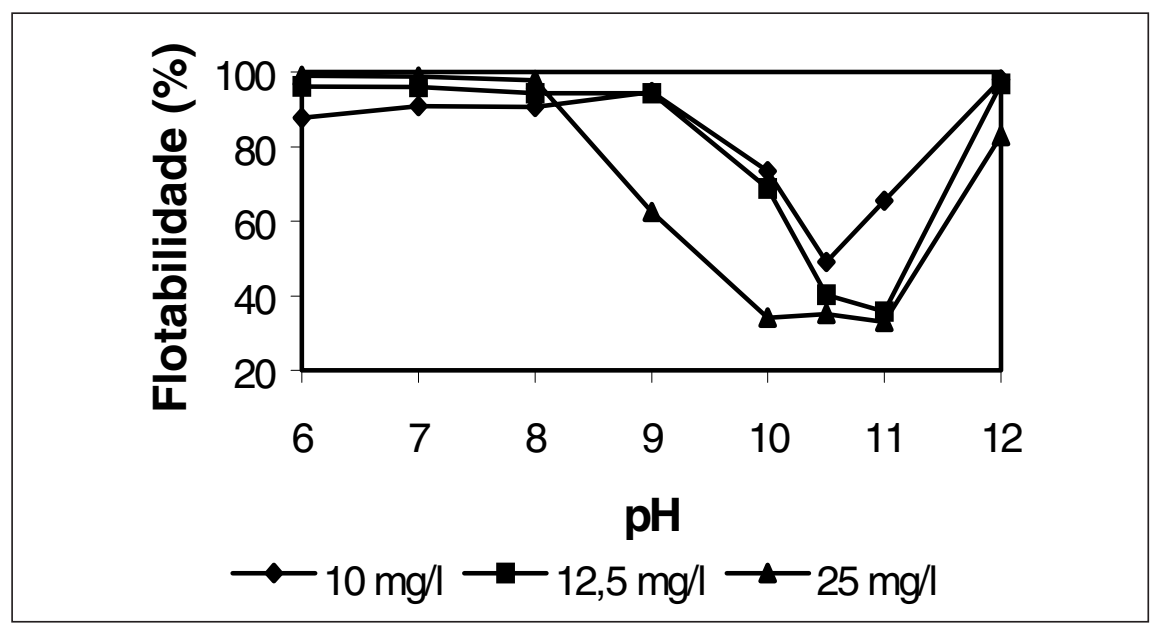

Figura 3 - Flotabilidade do quartzo em função do pH e da concentração de acetato de eteramina, Lima (1997), Lima e Brandão (1999). 
Pela fórmula anterior, verifica-se que a \% de sólidos na suspensão é uma variável, que deve ser levada em consideração para o levantamento da mobilidade eletroforática das partículas minerais. Por essa razão, através de ensaios preliminares, verificou-se que a \% de sólidos igual a $12 \%$ foi considerada ideal, uma vez que os resultados obtidos de $\mathrm{V}_{\varepsilon}$ foram mais reprodutíveis e não se verificava sedimentação das partículas.

Em uma primeira fase foram levantadas as curvas de potencial zeta da hematita e do quartzo em função do $\mathrm{pH}$ (6 a 12 , incluindo 10,5), condicionados em água destilada. Em uma segunda fase, foram levantadas as curvas de potencial zeta para as concentrações de $1,41 \times 10^{-4} \mathrm{M}$ e $1,41 \times 10^{-3} \mathrm{M}$ de acetato de eteramina, que correspondem a 5 e $50 \mathrm{mg} / \mathrm{l}$ nos ensaios de microflotação, para a amostra de hematita e concentrações de $7,38 \times 10^{-5} \mathrm{M}$; $2,83 \times 10^{-4} \mathrm{M} \mathrm{e} 3,54 \times 10^{-4} \mathrm{M}$ para a amostra de quartzo, que correspondem às dosagens de $5,12,5$ e $25 \mathrm{mg} / 1$ nos ensaios de microflotação. Deve-se salientar, nesse ponto, que todos os resultados obtidos foram confirmados pela repetição de todos os ensaios realizados.

\section{Resultados e discussão}

Os valores de potencial zeta da hematita e do quartzo em função do $\mathrm{pH}$ estão apresentados na Tabela 1, onde se observa que o ponto isoelétrico da hematita encontra-se entre os valores de pH 6 e 8,que está próximo ao valor 6, 9, obtido pelo método de Mular e Rbert's (1966) e que o potencial zeta do mineral em pH igual a 12 é de -3,35 volts. O potencial zeta do quartzo é negativo para todos os valores de $\mathrm{pH}$ medidos (6 a 12) e que os mesmos são bem mais negativos que no caso da hematita, exceto para o pH igual a 9, que não representa a tendência geral. Embora o que tenha sido medido nesse trabalho tenha sido o potencial zeta, pode-se inferir, através destes resultados, que a carga superficial do quartzo é bem mais negativa do que a da hematita, o que está de acordo com as afirmações de outros pesquisadores (Iwasaki, 1960 e Corrêa, 1982), pois os íons determinadores de potencial nesse caso é o $\mathrm{H}^{+}$e o $\mathrm{OH}^{-}$.

Pela Tabela 2, observa-se que o potencial zeta da hematita tornou-se ligeiramente menos negativo na presença de amina a $1,41 \times 10^{-4} \mathrm{M}$ e $1,41 \times 10^{-3} \mathrm{M}$, quando se comparam os valores de potencial zeta do mineral condicionado com água destilada (Tabela 1) e com amina (Tabela 2). Para a dosagem de $1,41 \times 10^{-3} \mathrm{M}$ de amina, 10 vezes maior que a concentração de $1,41 \times 10^{-4} \mathrm{M}$, observa-se que todos os valores de potencial zeta medidos foram menos negativos que para dosagem de $1,41 \times 10^{-4} \mathrm{M}$ nos valores de $\mathrm{pH}$ de 8 a 12 , exceto para o pH 9,que não representa a tendência geral. Observa-se, também, que em $\mathrm{pH} 6$ o potencial zeta positivo do mineral tornou-se ligeiramente menor, significando que, nesse valor de $\mathrm{pH}$, houve adsorção de amina em sítios negativos presentes em sua superfície. Essa diminuição da carga superficial do mineral na presença de amina sugere que ocorreu uma atração eletrostática entre a superfície do mineral carregada negativamente e o cátion eteramônio presentes na solução, que é coerente com as conclusões de Iwasaki et al. (1960), de Lima (1997) e de Lima e Brandão (1999).

Pela Tabela 3, observa-se que o potencial zeta do quartzo tornou-se menos negativo na presença de amina, quando se comparam os valores de potencial zeta do mineral condicionado com água destilada (Tabela 1) com os valores de po-

Tabela 1 - Potencial zeta da hematita e do quartzo condicionados com água destilada.

\begin{tabular}{c|c|c}
\hline pH & $\begin{array}{c}\text { Potencial zeta da } \\
\text { hematita (volts) }\end{array}$ & $\begin{array}{c}\text { Potencial zeta do } \\
\text { quartzo (volts) }\end{array}$ \\
\hline 6 & 0,024 & $-0,025$ \\
\hline 7 & - & $-0,027$ \\
\hline 8 & $-0,032$ & $-0,08$ \\
\hline 9 & $-0,070$ & $-0,051$ \\
\hline 10 & $-0,120$ & $-0,39$ \\
\hline 10,5 & $-0,250$ & $-0,53$ \\
\hline 11 & $-0,800$ & $-1,28$ \\
\hline 12 & $-3,350$ & $-10,80$ \\
\hline
\end{tabular}

Tabela 2 - Potencial zeta da hematita condicionada com acetato de eteramina a $50 \%$ de grau de neutralização nas concentrações de $1,41 \times 10^{-4} \mathrm{M}$ e $1,41 \times 10^{-3} \mathrm{M}$.

\begin{tabular}{|c|c|c|}
\hline pH & $\begin{array}{c}\text { Potencial zeta da } \\
\text { hematita a } 1,41 \times 10^{-4} \mathrm{M} \\
\text { (volts) }\end{array}$ & $\begin{array}{c}\text { Potencial zeta da } \\
\text { hematita a } 1,41 \times 10^{-3} \mathrm{M} \\
\text { (volts) }\end{array}$ \\
\hline 6 & 0,015 & 0,10 \\
\hline 8 & $-0,028$ & $-0,08$ \\
\hline 9 & $-0,048$ & $-0,053$ \\
\hline 10 & $-0,17$ & $-0,13$ \\
\hline 10,5 & $-0,21$ & $-0,19$ \\
\hline 11 & $-0,54$ & $-0,34$ \\
\hline 12 & $-3,38$ & $-3,20$ \\
\hline
\end{tabular}


tencial zeta do mesmo condicionado com amina (veja a dosagem de 7,38 $\times 10^{-5} \mathrm{M}$ da Tabela 3 ), que corresponde a curva de 5 $\mathrm{mg} / \mathrm{l}$ (dosagem ótima) dos ensaios de microflotação (Figura 2) em que não foi observada queda de flotabilidade do mineral até essa concentração. Esses resultados de potencial zeta do quartzo condicionado com amina sugere que a adsorção da amina sobre a superfície do quartzo se dá também através da atração eletrostática entre os íons eteramônio e a superfície do mineral carregada negativamente.

Pelo fato de o potencial zeta ser negativo (Tabela 1) e, conseqüentemente, a carga superficial do quartzo ser mais negativa que a da hematita a adsorção deste reagente sobre o mineral quartzo é maior que sobre a hematita, pois observou-se uma diminuição mais acentuada do potencial zeta negativo do quartzo que o da hematita.

Para a dosagem de $3,54 \times 10^{-4} \mathrm{M}$ de amina (Tabela 3), que corresponde à dosagem de 25mg/l da Figura 3, ocorreu a mudança do sinal de potencial zeta (medido no plano de cisalhamento da dupla camada elétrica) de negativo para positivo em $\mathrm{pH}$ entre 9 e 10 . Houve, portanto, a reversão de carga na interface quartzo/ solução aquosa. Segundo Parks (1975), esse fenômeno somente é possível através de adsorção específica de íons, presentes na solução, no plano interno de Helmholtz da dupla camada elétrica.

\section{Conclusões}

- O ponto isoelétrico da hematita ocorreu em pH entre 6 e 8.

- Os valores de potencial zeta do quartzo foram bem mais negativos que os da hematita. Logo, a atração de cátions eteramônio pelo quartzo é bem maior que pela hematita, o que explica a menor dosagem de amina necessária para a flotação do quartzo em relação à hematita.

- Houve diminuição de valor negativo do potencial zeta dos minerais condicionados com amina, especialmente no caso do quartzo, em relação àqueles valores quando os mesmos foram condicionados com água destilada.

- Observou-se a mudança de sinal do potencial zeta do quartzo de negativo para positivo entre os valores de $\mathrm{pH} 9$ e 10 para a dosagem de $4,1 \times 10^{-3} \mathrm{M}$.

\section{Referências bibliográficas}

ARAÚJO, A. C. Influência de ions de alumínio e caolinita na flotação catiônica de quartzo e hematita. Belo Horizonte: UFMG, Escola de Engenharia, Universidade Federal de Minas Gerais, 1982. 121p. (Dissertação de Mestrado em Engenharia Metalúrgica e de Minas - Tecnologia Mineral).

HOUOT, R. Beneficiation of iron ore by flotation - review of industrial and potencial applications. International Journal of Mineral Processing. Amsterdam: Elsevier Scientific Publishing Company, 10, p. 183204, 1983.

IWASAKI, I., COOKE, S. R. B., COLOMBO, A F. Flotation characteristics of goethite. Washington, United States of Interior, Bureau of Mines, Report of Investigations 5593, 1960. 25p.

LIMA, R. M. F. Adsorção de amido e de amina na superficie da hematita e do quartzo $e$ sua influência na flotação. Belo Horizonte: UFMG, Escola de Engenharia, Universidade Federal de Minas Gerais, 1997. 238p. (Tese de Pós- Graduação em Engenharia Metalúrgica e de Minas - Tecnologia Mineral).

LIMA, R. M. F., BRAND ̃̃O, P. R. G. Flotabidade da hematita e do quartzo com alquileteramina na ausência e presença de amido In: SIMPÓSIO BRASILEIRO DE MINÉRIOS DE FERRO, Ouro Preto, 1999. p.172-185.

MULAR, A.C., ROBERTS,R. B. A simplified method to determine isoeletric points of oxides. CIM Trnsactions, v. 69, p.438-439, 1966.

PARKS, G. Adsorption in the marine environment. In: RILEY, J.P., SKIRROW, G. Chemical Oceanography. 2. ed. Londom, New York, San Francisco: Academic press, 1975. v. I. Chapter 4, p. 241-308.

QUAST, K. B. A review of hematite flotation using 12-Carbon chain collectores. Minerals Engeneering. v.13, n.13, p. 13611376, 2000

ROSSI, E. E., ARRIETA, C., CIRIBENI, V., FERRETTI, R.J. Depression areas in flotation graphs produced by the adsorption of a second layer in froth flotation. Minerals \& Metallurgical Processing. v. 8, n. 1, p.7-15, February 1991.

Tabela 3 - Potencial zeta do quartzo na presença de acetato de eteramina nas concentrações de $7,38 \times 10^{-5} \mathrm{M}, 2,38 \times 10^{-4} \mathrm{M}$ e $3,54 \times 10^{-4} \mathrm{M}$.

\begin{tabular}{|c|c|c|c|}
\hline PH & $\begin{array}{c}\text { Potencial zeta do quartzo } \\
\text { a } 7,38 \times 10^{-5} \mathrm{M} \text { (volts) }\end{array}$ & $\begin{array}{l}\text { Potencial zeta do quartzo } \\
\text { a } 2,38 \times 10^{-4} \mathrm{M} \text { (volts) }\end{array}$ & $\begin{array}{c}\text { Potencial zeta do quartzo } \\
\text { a } 3,54 \times 10^{-4} \mathrm{M} \text { (volts) }\end{array}$ \\
\hline 6 & $-0,035$ & $-0,008$ & $-0,038$ \\
\hline 7 & $-0,038$ & $-0,006$ & $-0,023$ \\
\hline 8 & $-0,026$ & $-0,04$ & $-0,012$ \\
\hline 9 & $-0,036$ & $-0,100$ & $-0,0091$ \\
\hline 10 & $-0,25$ & $-0,13$ & 0,13 \\
\hline 10,5 & $-0,35$ & $-0,20$ & 0,34 \\
\hline 11 & $-0,68$ & $-0,42$ & 0,66 \\
\hline 12 & $-0,97$ & $-2,32$ & 7,50 \\
\hline
\end{tabular}

Artigo recebido em 30/09/2002 e aprovado em 10/01/2003. 